\title{
REMOTE SENSING BASED ANALYSIS OF THE ROLE OF LAND USE/LAND COVER ON SURFACE TEMPERATURE AND TEMPORAL CHANGES IN TEMPERATURE A CASE STUDY OF AJMER DISTRICT, RAJASTHAN
}

\author{
Adil Hussain, Parul Bhalla and Sarvesh Palria \\ Department of Remote Sensing \& Geo-informatics, M.D.S. University, Ajmer \\ hussain.adil01@gmail.com
}

KEY WORDS: Surface temperature, Processing, Analysis, Correlation, Comparison, Sampling, Satellite, Temporal

\begin{abstract}
:
An attempt has been made in this research to analyze temporal variations in surface temperature in Ajmer District Rajasthan. The research is carried out to assess the relationship between the land surface temperatures (LST) and land cover (LC) changes both in quantitative and qualitative ways in Ajmer District area using Landsat TM/ETM+ data over the period 1989 to 2013 .in this period we used three temporal TM/ETM data 1989, 2001 and 2013. Remote sensing of Land surface temperature (LST) has traditionally used the Normalized Difference Vegetation Index (NDVI) as the indicator of vegetation abundance to estimate the land surface temperature (LST)-vegetation relationship. Unsupervised classification methods have been taken to prepare the LC map. LST is derived from the thermal band of Landsat TM/ETM+ using the calibration of spectral radiance and emissivity correction of remote sensing. NDVI is derived from the NIR \& RED Band using image enhancement technique (Indices). Arc-GIS have been utilized for data visualization. This procedure allowed analyzing whether LULC classes match LST classes. However, the results of such overlaying are hard to interpret. LST and LULC maps of these areas give the understanding on how the classes and corresponding LST have changed from one date to the other. Another option is to collect statistical data. it was impossible to calculate linear regression between LULC map and LST map. A solution to that matter is to use Normalized Vegetation Index (NDVI) instead of LULC classification result.
\end{abstract}

\section{INTRODUCTION}

Land surface temperature is an important factor in global changes in estimating radiation budget in heat balance studies and as a control for climate mode. It forms the basic forth application of water and energy balance modeling's(van de grinds et, al 1993).The knowledge's of the surface temperature is important to a range of issue and themes in earth science such as global environment changes, human-environment interaction and more specifically to urban climatology.

Surface temperature can be acquired directly from ground measurement but these measurements cannot be generalized since surface temperature varies considerably from one type of surface to another on the other hand satellite measurement are not subject to arbitrary extrapolation .They are area averaged rather than point values and can be acquired a regular temporal basis (Goita and Royer, 1997).

Rise in urbanization (includes both natural increase and migration) and rapid industrialization is one of the major causes of climate changes all over the word. Today the most imperative problem in urban areas is increasing surface temperature because of dramatic alteration of the natural surface as natural vegetation is removed and replace by nonevaporating, non-transpiring surface (e.g. stone, metal, concrete etc.)

\section{STUDY AREA}

Ajmer is situated in the geographic centre of Rajasthan and lies about $135 \mathrm{~km}$ 's south-west of the state capital, Jaipur. Ajmer covering geographical area of $8,481 \mathrm{sq}$. $\mathrm{km}$. it is surrounded by the Aravalli mountain ranges in the center of Rajasthan state, surrounded by three hill of Aravalli ranges at an average of 486.0 meter above MSL.

\begin{tabular}{|l|l|}
\hline Coordinates & $\begin{array}{l}25^{0} 38^{\prime} \& 26^{0} 58^{\prime} \text { N latitude, } 73^{0} 54^{\prime} \& 75^{\circ} \\
22^{\prime} \text { E longitude }\end{array}$ \\
\hline Area & 8,481 sq km \\
\hline Tehsil & $\begin{array}{l}\text { Ajmer District is sub-divided 12 tehsils } \\
\text { Ajmer, Beawar, Kekri, Kishangarh, } \\
\text { Nasirabad, Masooda, Roopangarh, Todgarh, } \\
\text { Pushkar, Sarwar, Peesangan and Bhinay. }\end{array}$ \\
\hline Temperature & $\begin{array}{l}\text { Average daily temperature of about } 30{ }^{\circ} \mathrm{C} \\
\left(86{ }^{\circ} \mathrm{F}\right) \text { Maximum temperature } 44^{\circ} \mathrm{C}, \text { while } \\
\text { minimum is nearly } 22^{\circ} \mathrm{C}\end{array}$ \\
\hline Rainfall & $\begin{array}{l}\text { Ajmer has a hot semi-arid climate with over } \\
55 \text { centimeters }(25.4 \text { in) of rain every year, }\end{array}$ \\
\hline Association & $\begin{array}{l}\text { Aravalli mountain ranges in the center of } \\
\text { Rajasthan state, surrounded by three hill of } \\
\text { Aravalli ranges e.g.. Nag Hill, Madar Hill } \\
\text { \&Taragher Hill. }\end{array}$ \\
\hline Elevation & Average of 486.0 meter above MSL. \\
\hline
\end{tabular}

Table2.1:- Ajmer District Location Information

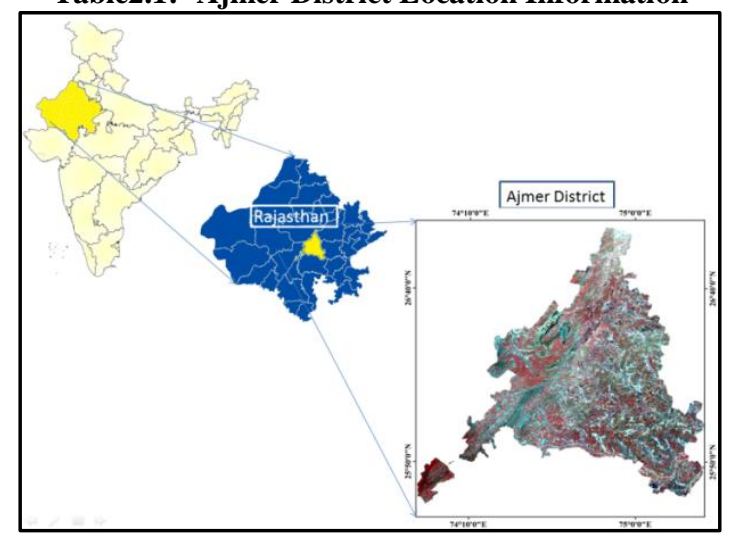

Figure 2.1: - Location map of Ajmer District 


\section{DATA USED AND METHODOLOGY}

For this research work we have need of Satellite data to estimate Land Surface Temperature and relationship between Land use and Land cover of a large scale area. On the other hands we have need secondary data likewise Survey of India Toposheets of the study area and roads, settlement, Study area boundary shape file and sensors calibrations Info. Acquire three temporal data for this project, 1989, 2001 and 2013 year of data acquired by Landsat series satellite. Landsat $5 \mathrm{TM}$ data used for 1989, Landsat 7 TM used for 2001 and Landsat 8 OLI/TIRS data used for 2013. . Imagery from These Satellites is distributed for free from the following USGS Website: http://earthexplorer.usgs.gov/.

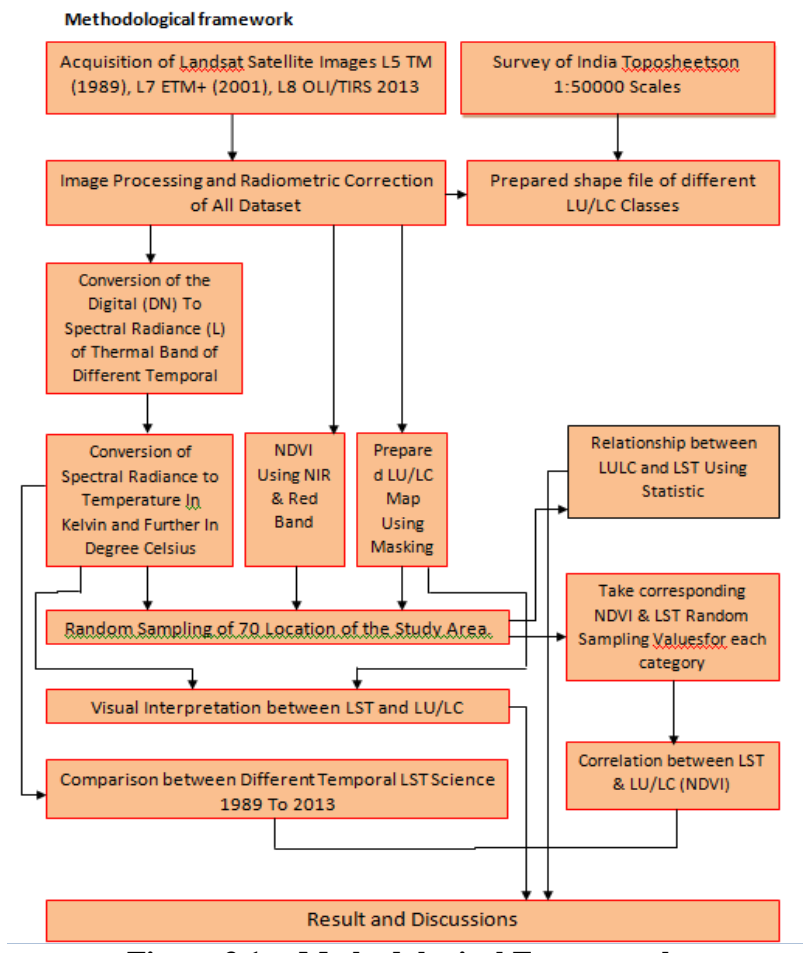

Figure 3.1: - Methodological Frame work

3.1 Acquisition of Landsat Satellite Images L5 TM (1989), L7 ETM+ (2001), L8 OLI/TIRS 2013

\begin{tabular}{|c|l|l|l|l|}
\hline & Satellite & Path/Row & Dates & Resolution \\
\hline \multirow{2}{*}{1} & Landsat-5 & $147 / 42$ & $09-10-1989$ & Optical-30m \\
& TM & $148 / 41$ & $16-10-1989$ & TIR- 120m \\
& & $148 / 42$ & $14-09-1989$ & \\
\hline 2 & Landsat-7 & $147 / 42$ & $19-09-2001$ & Optical-30m \\
& ETM+ & $148 / 41$ & $24-11-2001$ & TIR- 60m \\
& & $148 / 42$ & $26-09-2001$ & \\
\hline 3 & Landsat-8 & $147 / 42$ & $27-10-2013$ & Optical-30m \\
& OLI/TIRS & $148 / 41$ & $18-10-2013$ & TIR-100m \\
& & $148 / 42$ & $18-10-2013$ & \\
\hline
\end{tabular}

Table 3.1: - List of the Satellite data used

\subsection{Image Processing \& Radiometric Correction of all Dataset.}

First we did radiometric correction of the dataset using ENVI 4.8 software in which we used radio metric correction tool for correction the dataset. After this we did Geo-metric correction of all the dataset using Re-projection tool of the ERDAS 9.2

\subsection{Prepared LU/LC Map Using Masking}

It is very helpful to analyze research data and achieve our objective. We did $1^{\text {st }}$ level classification on the study area. In this we classified the data into major categories. We found that some mixed categories like that: wasteland and settlement, forestland and agriculture etc. mixed in each other. For the solution of this problem we did masking of the mixed categories. We used ERDAS modeler to perform this function. We have taken unsupervised classification data and in the vector object taken shape file which is masked over the classified data. In the function object taken "either" function for achieve this objective for example "EITHER 6 IF (\$n2_settlement_2001=1) OR \$n1_recode_ajmer_2001_classi OTHERWISE".

\subsection{Prepared NDVI}

NDVI is to use show the relationship between Land surface temperature and Land use/ Land cover using the linear regression correlation method. Because of the nature of LU/LC it was not possible to calculate the correlation between LU/LC and Land Surface temperature. A solution to that matter is to use Normalized Vegetation Index (NDVI) instead of LULC classification result.

\section{General formula NDVI $=($ Infra - Red $) /($ Infra. + Red $)$}

The value is between +1 (vigor) $\sim-1$ (stress)

In other words, NDVI value is related to LULC class. Linear regression between NDVI and LST has been calculated.

\subsection{Converting Landsat TM and ETM+ thermal bands to temperature}

It is possible to convert these DNs to degrees Kelvin using a two (or optionally three) step process. The first step is to convert the DNs to radiance values using the bias and gain values.

a)Spectral Radiance Scaling Method the formula used in this process is as follows:

\section{$\mathrm{CV}_{\mathrm{RI}}=\quad\left(\left(\mathrm{LMAX}_{\lambda}-\mathrm{LMIN}_{\lambda}\right) /(\mathbf{Q C A L M A X}-\mathrm{QCALMIN})\right)$ $*($ QCAL- QCALMIN $)+$ LMIN $_{\lambda}$}

Where:

CVR1 is the cell value as radiance

$\mathrm{QCAL}=$ digital number

LMIN $\lambda=$ spectral radiance scales to QCALMIN

LMAX $\lambda=$ spectral radiance scales to QCALMAX

QCALMIN = the minimum quantized calibrated pixel value (typically $=1$ )

QCALMAX $=$ the maximum quantized calibrated pixel value.

b) Convert Radiance to Kelvin the formula to convert radiance to temperature without atmospheric correction is:

$$
\begin{aligned}
& \mathbf{T}_{\mathbf{K}}= \mathbf{K}_{\mathbf{2}} / \ln \left(\left(\mathbf{K}_{\mathbf{1} * /} \mathbf{C} \mathbf{V}_{\mathbf{R I}}\right)+\mathbf{1}\right) \\
& \text { Where: } \\
& \text { T is degrees Kelvin } \\
& \text { CVR1 is cell value as radiance } \\
& E \text { is emissivity (typically } \mathbf{0 . 9 5}
\end{aligned}
$$




\begin{tabular}{|l|l|c|c|}
\hline & Landsat TM & $\begin{array}{l}\text { Landsat } \\
\text { ETM }\end{array}$ & $\begin{array}{l}\text { Landsat8 } \\
\text { OLI/TIRS }\end{array}$ \\
\hline K1 & 607.76 & 666.09 & 774.89 \\
\hline K2 & 1260.56 & 1282.71 & 1321.8 \\
\hline
\end{tabular}

Table 3.2:- Sensors constant Calibration information

c) Kelvin to degree in Celsius:

$$
T_{C}=T_{K}-273
$$

After all this, Land Surface Temperature Dataset ready to use it.

\subsection{Random Sampling of the study area}

In order to establish the relationship between LST and corresponding land use/cover type, 70 sample points were selected randomly from different land use/cover types in the study area. About 10-10 samples were selected from each land use/cover types, e.g., Forestland, Agriculture, Fallow land, Water body, industry, Settlement and Wasteland. The thermal characteristics of these 70 locations are studied across the all temporal dataset.

\subsection{Relationship between LULC and LST Using Statistic}

The average temperature of each land use/cover category for each temporal LST was calculated using the formula of simple arithmetic mean.

3.8 Relationship between LULC and LST by the linear regression between LST \& LU/LC (NDVI)

NDVI values are related to LULC class. Linear regression between NDVI and LST has been calculated using the random sampling values of different temporal LST and their corresponding NDVI values it is helpful to investigate the spatial pattern of LST.

\subsection{Visual Interpretation between LST and LU/LC}

A focus area with significant LULC transition was chosen for each Temporal Dataset. LST and LULC maps of these areas give the understanding on how the classes and corresponding LST slices have changed from one date to the other. Arc-GIS have been utilized due to its better capabilities for data visualization.

\subsection{Comparison between Different Temporal LST Science 1989 To 2013}

\subsubsection{Comparison done by the Visual Interpretation}

Same procedure follows for the comparison by the visual interpretation.

\subsubsection{Comparison done by the Statistic}

The average temperature of each Land use/Land cover category for each temporal LST maps was calculated using the formula of simple arithmetic mean. After this compared each land use/Land cover category minimum, maximum and average temperature of the other temporal LST maps category and calculate the minimum, maximum and average temperature changes.

\section{RESULT \& DISCUSSION}

Within the frame work of research objectives, the following result and discussion were deriving. First of all, we deals with the Land use/ land cover result 1989, 2001 and 2013 respectively.

\subsection{Land Use/Land Cover Classification Result and Accuracy Assessment}

Differences between classification results and reference data are known as classification errors. One of the most common methods of classification accuracy assessment is error matrix or confusion matrix. This matrix contains a category comparison of relationship between known, ground-truth data and classification results for the same category.

\subsubsection{Land Use/ Land Cover Classification Result and Accuracy Assessment of Year 1989}

Overall Classification Accuracy $=\mathbf{8 0 . 0 0 \%}$, Overall Kappa Statistics $\quad=\mathbf{0 . 7 8 7 6}$

\subsubsection{Land Use/ Land Cover Classification Result and Accuracy Assessment of Year 2001}

Overall Classification Accuracy $=\mathbf{8 3 . 0 0 \%}$, Overall Kappa Statistics $\quad=\mathbf{0 . 7 5 5 0}$

\subsubsection{Land Use/ Land Cover Classification Result and} Accuracy Assessment of Year 2013

Overall Classification Accuracy $=\mathbf{8 5 . 0 0 \%}$, Overall Kappa Statistics $\quad=\quad \mathbf{0 . 7 8 7 6}$

\subsubsection{Change Rate of LU/LC Since 1989 to 2001}

\begin{tabular}{|c|c|c|c|c|}
\hline Class & Year 1989 & $\frac{\text { Are in Sq. }}{\frac{\mathrm{Km} \text { Year }}{2001}}$ & Changes & $\begin{array}{l}\text { Change } \\
\text { rate in } \\
\text { Percent }\end{array}$ \\
\hline Water body & 72.12 & 159.79 & 87.67 & 121.56 \\
\hline Forestland & 328.63 & 218.75 & -109.88 & -33.43 \\
\hline Agriculture & 3545.25 & 2053.95 & -1491.3 & -42.06 \\
\hline Fallow land & 2018.58 & 1923.55 & -95.02 & -4.70 \\
\hline Wasteland & 2481.49 & 4030.51 & 1549.02 & 62.42 \\
\hline Settlement & 31.99 & 74.54 & 42.54 & 132.94 \\
\hline Industry & 2.78 & 8.04 & 5.26 & 188.67 \\
\hline
\end{tabular}

Table 4.1: - Change rate of Land use/ Land cover from 1989 To 2001 


\subsubsection{Change Rate of LU/LC Since 2001 to 2013}

\begin{tabular}{|c|c|c|c|c|}
\hline Classes & $\begin{array}{c}\text { Year } \\
2001\end{array}$ & $\begin{array}{c}\text { Area in Sq. } \\
\text { Km Year } \\
2013\end{array}$ & Changes & $\begin{array}{c}\text { Change } \\
\text { rate in } \\
\text { Percent }\end{array}$ \\
\hline Water body & 159.79 & 150.68 & -9.11 & -5.70 \\
\hline Forestland & 218.75 & 299.77 & 81.028 & 37.04 \\
\hline Agriculture & 2053.95 & 2871.72 & 817.76 & 39.81 \\
\hline Fallow land & 1923.55 & 2895.10 & 971.55 & 50.50 \\
\hline Wasteland & 4030.51 & 2163.41 & -1867.10 & -46.32 \\
\hline Settlement & 74.54 & 85.20 & 10.66 & 14.30 \\
\hline Industry & 8.04 & 13.11 & 5.06 & 62.96 \\
\hline
\end{tabular}

Table 4.2: - Change rate of Land use/ Land cover from 2001 to 2013

\subsubsection{Change Rate of LU/LC from 1989 to 2013 Year}

\begin{tabular}{|l|c|c|c|c|c|}
\hline & $\begin{array}{c}\text { Year } \\
\text { Classes }\end{array}$ & $\begin{array}{c}\text { Area in Sq. } \\
\text { Km Year } \\
2089\end{array}$ & Changes & $\begin{array}{c}\text { Change } \\
\text { rate in } \\
\text { Percent }\end{array}$ \\
\hline Water body & 72.12 & 150.68 & 78.55 & 108.9 \\
\hline Forestland & 328.63 & 299.77 & -28.85 & -8.78 \\
\hline Agriculture & 3545.25 & 2871.72 & -673.53 & -18.99 \\
\hline Fallow land & 2018.58 & 2895.10 & 876.52 & 43.42 \\
\hline Wasteland & 2481.49 & 2163.41 & -318.07 & -12.81 \\
\hline Settlement & 31.99 & 85.20 & 53.20 & 166.27 \\
\hline Industry & 2.78 & 13.11 & 10.32 & 370.45 \\
\hline
\end{tabular}

Table 4.3: - Change rate of Land use/ Land cover from 1989 to 2013

These changes in Land use and Land cover category effect the Land Surface Temperature pattern on the study area from 1989 to 2013 .

\subsection{Land Surface Temperature and LU/LC Relationship}

\subsubsection{Using the Visual Interpretation Technique}

A focus area with significant LULC transition was chosen for each Temporal Dataset. LST and LULC maps of these areas give the understanding on how the classes and corresponding LST slices have changed from one date to the other.

Visual Interpretation of different temporal LST with their corresponding LU/LC is showed in figure 4.1

Through the Visual interpretation, we found that LST and Land use/ Land cover are related to each other.

When LU/LC of the area changes then the temperature of the area also changes. Water body has a lowest temperature in the study area, fallow land has a highest temperature in the study area and Industry and settlement have a moderate temperature.
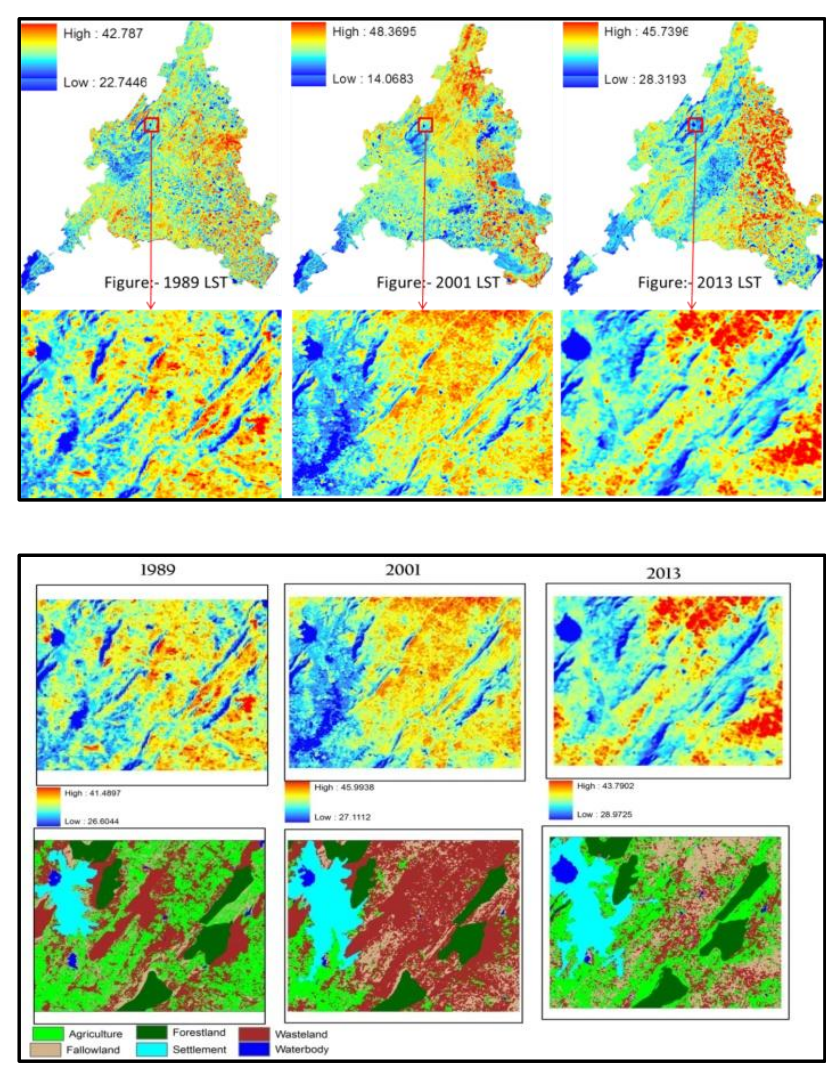

Figure 4.1: - Visual Interpretation of LST and their corresponding LU/LC of 1989, 2001 and 2013 year.

\subsubsection{Relationship on the basis of Statistics and Graphically}

Year 1989

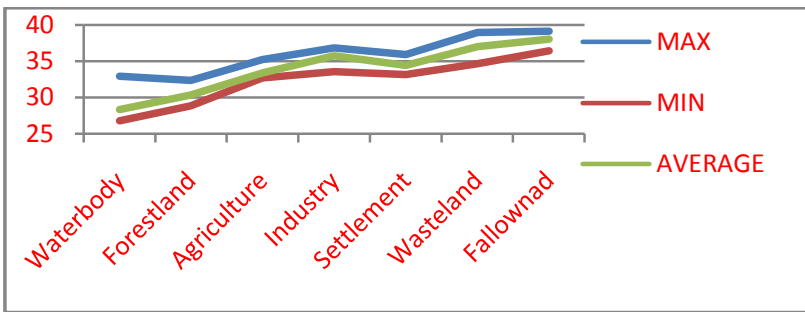

Figure 4.2:-Land surface temperature of different LU/LC of Landsat5 TM band 6 (1989)

Year 2001

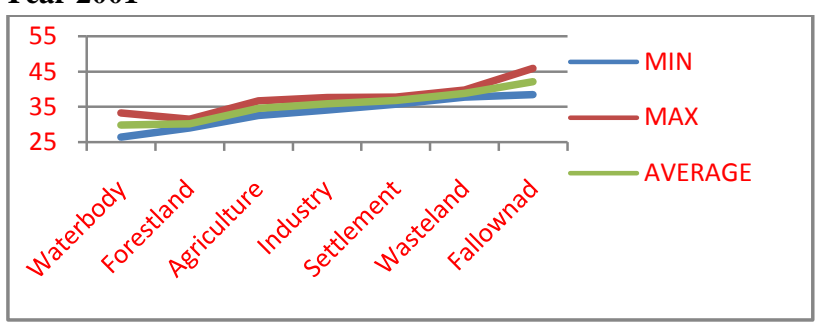

Figure 4.3:-Land surface temperature of different LU/LC Landsat7 ETM+ band 6(2001) 
Year 2013

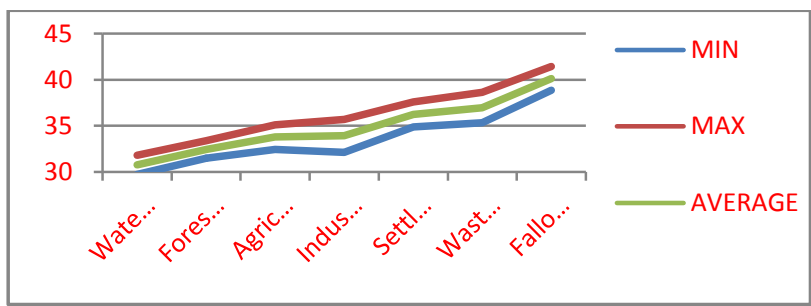

Figure 4.4:-Land surface temperature of different LU/LC of Landsat8 OLI/TIRS band 10(2013)

We found the Sequenced of the LU/LC categories which are responsible to increment in temperature of the LST maps in uniform manner show; Water body, Forestland, Agriculture, Industry, Settlement, Wasteland and Fallow land. This sequence of LU/LC Categories is responsible for sustainable increment in temperature. It means that Land Surface Temperature distribution pattern is depending on the LU/LC categories. Where are the water body, Forestland and Agriculture situated temperature of the area is lower in comparison of other LU/LC categories.

\subsubsection{Relationship on the basis of Linear Regression method of 1989, 2001 and 2013 year}

Due to the nature of LULC map, it was impossible to calculate linear regression between LULC map and LST map. A solution is to that matter is to use Normalized Vegetation Index (NDVI) instead of LULC classification result.

We performed linear regression method between LST map and their corresponding NDVI using the corresponding random sampling values of 1989, 2001 and 2013 year datasets of each LU/LC Categories with their corresponding NDVI values.

For Example: -

4.2.3.1 Linear Regression between LST \& NDVI of Year 1989

\section{$\underline{\text { Agriculture }}$}

\begin{tabular}{|l|l|l|l|l|l|l|l|l|l|}
\hline $\begin{array}{l}\text { N } \\
\text { D } \\
\text { V } \\
\text { I }\end{array}$ & 0.31 & 0.261 & 0.403 & 0.466 & 0.393 & 0.432 & 0.392 & 0.461 & 0.31 \\
\hline $\begin{array}{l}\text { L } \\
\text { S }\end{array}$ & 33.22 & 35.22 & 33.02 & 32.67 & 33.29 & 33.34 & 33.29 & 32.98 & 33.49 \\
T & & & & & & \\
\hline
\end{tabular}

Table 4.4: - Sampling values of the Agriculture of the NDVI \&LST of 1989 year

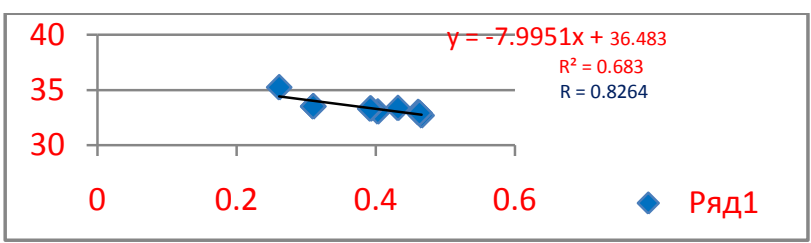

Figure 4.5:- Correlation between NDVI and LST of the Agriculture of the 1989 year
In all LU/LC Categories of the all temporal dataset procedure is remaining same.

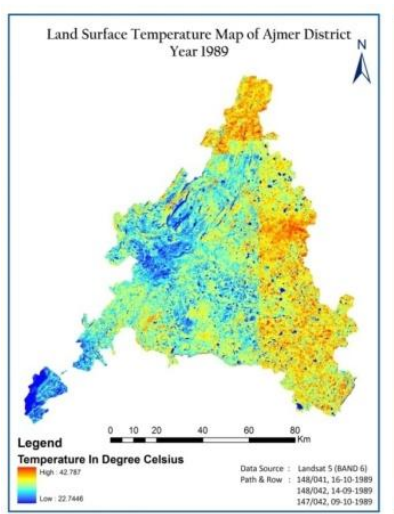

LST Range: 22.7446 - 42.787

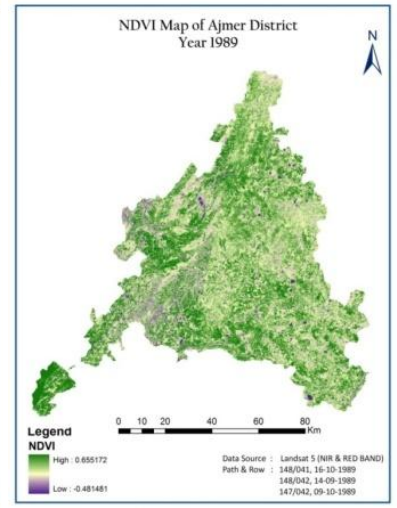

NDVI Range: - (-0.4814)-(0.6551)
Figure 4.6: -LST and NDVI Maps of 1989 year

\subsubsection{Linear Regression between LST \& NDVI of Year 2001}

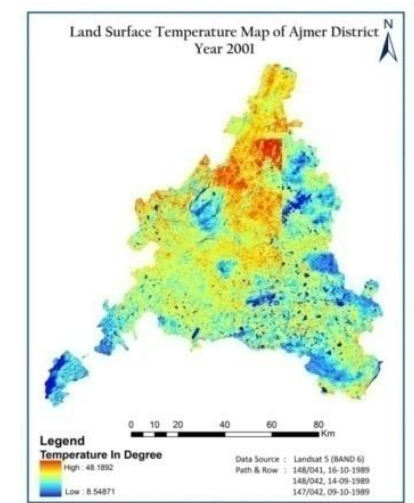

LST Range: - 8.548-48.189

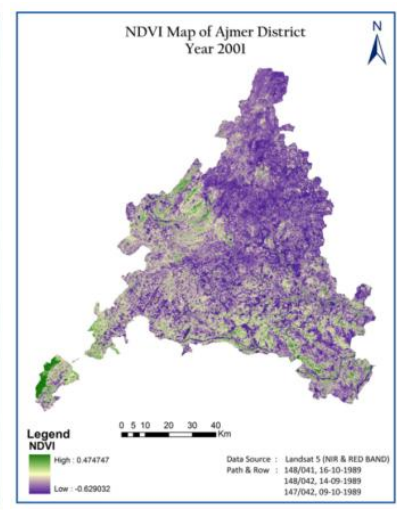

NDVI Range: - (-0.6290 to 0.4747$)$
Figure 4.7: - LST and NDVI Maps of 2001 year

\subsubsection{Linear Regression between LST \& NDVI of Year} 2013



LST Range: - 28.3671- 45.8614

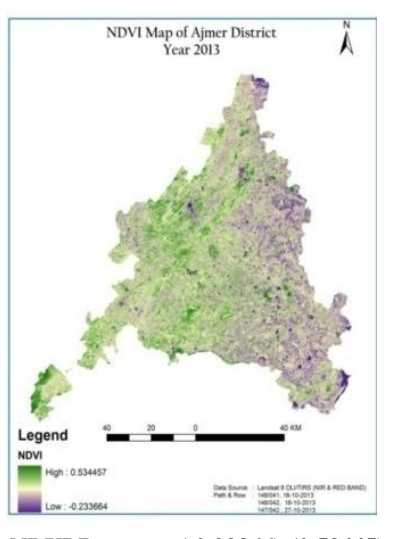

NDVI Range: - (-0.23366)-(0.53445)
Figure 4.8: -LST and NDVI MPAS of 2013 year

We observed that, in year 1989 all these LU/LC categories are having negative correlation with LST and NDVI except water body. In year 2001, we also observed that, all these LU/LC 
categories are having negative correlation with LST and NDVI except water body. In year 2013, above describe condition occur.

These entire LU/LC categories are having negative correlation with LST and NDVI except water body. It means that each category like; Fallow land, Wasteland, Settlement, industry severity are increased then the NDVI values of this corresponding category is decreases it means temperature of these categories increase. In case of Forestland and Agriculture categories Quality are increases than the NDVI values of this corresponding category is increased it means temperature of these categories decreases.

In case of water body positive correlation occur with LST and NDVI maps. When the NDVI values are increases then the temperature values also increases. In the water NDVI values are increases it means quality of the water is decreases because pure water having -0 NDVI it shows that when the NDVI values of the water body increases then the quality of the water is decrease and result is that the temperature of the Water body increase is increase then the NDVI values of this corresponding category is decrease it means temperature is decrease. So, water body one and only categories which is having positive correlation with LST and NDVI maps.

\subsection{Temporal changes in Land Surface Temperature Science 1989 to 2013using statistic}

\subsubsection{Using the Calculate Statistic}

\subsubsection{Land Surface Temperature Changes from 1989 to 2001}

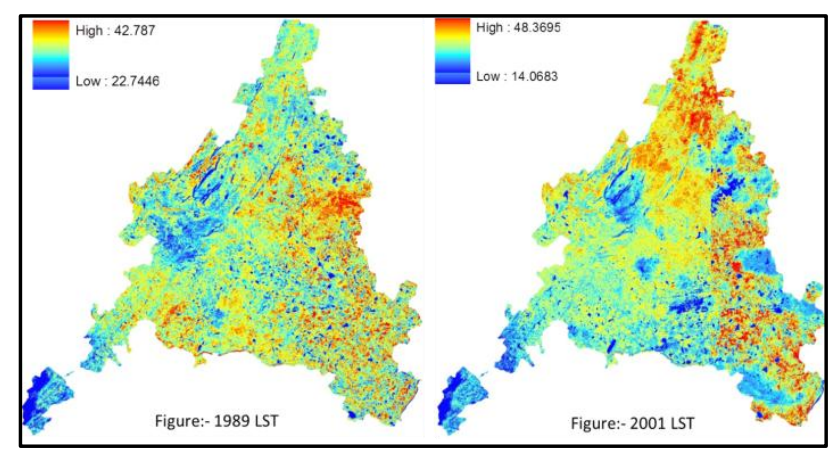

Figure 4.9: - Show the 1989 and 2001 LST Maps and Changes in Temperature Range

When we analyze the 1989 to 2001 LST maps we observed that 1989 year LST map has maximum 42.78 and minimum 22.7448 degree in Celsius than 2001 year LST map has maximum 48.36 and minimum 14.06 degree in Celsius. Changes in temperature range from 1989 to 2001; region is that some area of the 2001 year data covers by the clouds. Another thing is that maximum temperature of the 2001 LST map also increases because of the 2001 year having minimum rainfall at September to October in comparison to other temporal datasets.
We observed that land Surface Temperature of overall study area is increase $\mathbf{5 . 5 8 2 5}^{\circ} \mathrm{C}$ from 1989 to 2001 year.

\begin{tabular}{|c|c|c|c|}
\hline & 1989 Ave. & 2001 Ave & $\begin{array}{c}\text { Changes in } \\
\text { Degree Celsius }\end{array}$ \\
\hline Water body & 25.795 & 28.396 & 2.601 \\
\hline Forestland & 28.688 & 29.43 & 0.742 \\
\hline Agriculture & 31.969 & 32.283 & 0.314 \\
\hline Settlement & 34.72 & 36.086 & 1.366 \\
\hline Industry & 35.997 & 37.39 & 1.393 \\
\hline Wasteland & 38.23 & 39.819 & 1.589 \\
\hline Fallow land & 39.109 & 43.13 & 4.021 \\
\hline
\end{tabular}

Table 4.5: - Average temperature of 1989, 2001 \& Changes in Temperature from 1989 to 2001

\subsubsection{Land Surface Temperature Changes from 2001 to 2013}

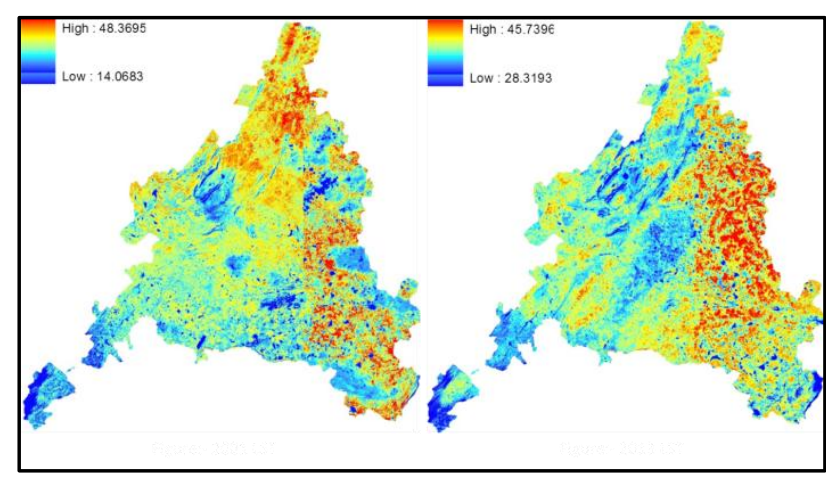

Figure: - 2001 LST

Figure:- 2013 LST

Figure 4.10: - 2001 and 2013 LST Maps and Changes in Temperature Range

We observed that land Surface Temperature of overall study area is decrease $\mathbf{- 2 . 6 2 9 9}{ }^{\circ} \mathrm{C}$ from 2001 to 2013 year. Region is that in year 2001 rainfall is low. Temperature is going on high on this year.

Land Surface Temperature of overall study area of Different land use and land cover categories is changed which shown in table 4.6.

\begin{tabular}{|c|c|c|c|}
\hline & 2001 Ave. & 2013 Ave. & $\begin{array}{c}\text { Changes in Degree } \\
\text { Celsius }\end{array}$ \\
\hline Water body & 28.396 & 29.928 & 1.532 \\
\hline Forestland & 29.43 & 32.956 & 3.526 \\
\hline Agriculture & 32.283 & 34.566 & 2.283 \\
\hline Settlement & 36.086 & 35.865 & -0.221 \\
\hline Industry & 37.39 & 35.009 & -2.381 \\
\hline Wasteland & 39.819 & 39.412 & -0.407 \\
\hline Fallow land & 43.13 & 40.713 & -2.417 \\
\hline
\end{tabular}

Table 4.6:- Average Temp. of 2001, 2013 \& Changes in Temperature from 2001 to 2013.

Finally we observed that overall study area temperature decrease from 2001 to 2013 year. Some of categories temperature is increases and some of categories temperature is decreases from 2001 to 2013 year. 


\subsubsection{LST Changes from 1989 to 2013}

We observed that land Surface Temperature of overall study area is increase 2.9526 Degree in Celsius From 1989 to 2013 year.

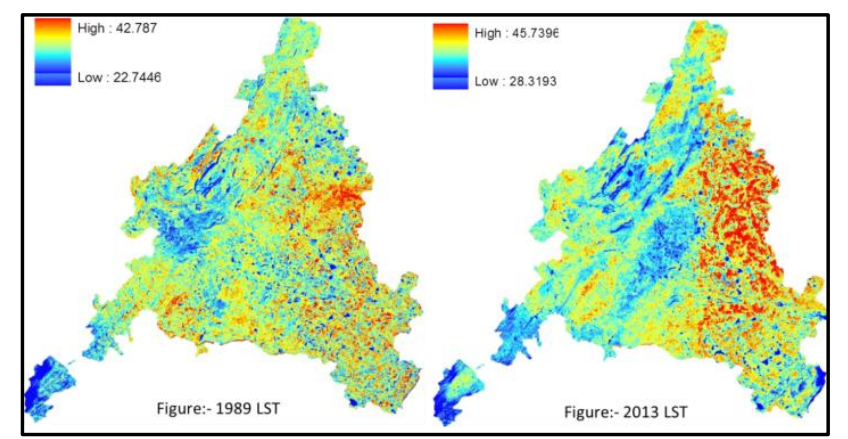

Figure 4.11: - Show the 1989 and 2013 LST Maps and Changes in Temperature Range

\begin{tabular}{|c|c|c|c|}
\hline & 1989 Ave. & 2013 Ave. & $\begin{array}{c}\text { Changes in } \\
\text { Degree Celsius }\end{array}$ \\
\hline Water body & 25.795 & 29.928 & 4.133 \\
\hline Forestland & 28.688 & 32.956 & 4.268 \\
\hline Agriculture & 31.969 & 34.566 & 2.597 \\
\hline Settlement & 34.72 & 35.865 & 1.145 \\
\hline Industry & 35.997 & 35.009 & -0.988 \\
\hline Wasteland & 38.23 & 39.412 & 1.182 \\
\hline Fallow land & 39.109 & 40.713 & 1.604 \\
\hline
\end{tabular}

Table 4.7: -Average Temperature of 1989, 2013 \& Changes in Temperature from 1989 to 2013.

Finally we observed that overall study area temperature increase since 1989 to 2013 year. All the LU/LC categories temperature is increases except industry.

4.3.2 Land Surface Temperature changes between different temporal Land Surface Temperature data show by the Visual interpretation.

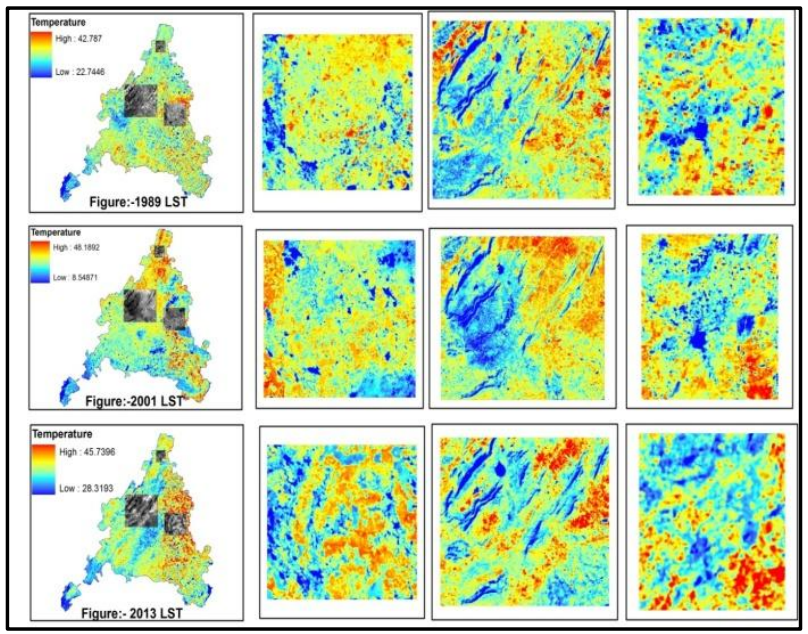

Figure 4.12: - Visually shows the changes in temperature since 1989 to 2013 year
In order to relate Land Surface temperature with other Land Surface Temperature, both LST map and other corresponding LST maps were imported to Arc-GIS. This procedure allowed analyzing whether LULC classes match LST classes. However, the results of such overlaying are hard to interpret. Instead, a focus area with significant LULC transition was chosen for each category. In 1989 to 2001 through the visual interpretation we observed that the temperature of both LST and their corresponding LST increased in such a manner and 2001 to 2013 visual interpretation we observed that the temperature of both LST and their corresponding LST increases and some portion of the corresponding LST is decrease in such a manner. This is only way to understand the changes in temperature between different temporal datasets. It means that trough this we got only qualitative information not quantitative information of the different temporal datasets.

\section{RECOMMENDATIONS:}

- Coarser resolution satellite dataset did not give much information of the surface temperature related to heterogeneous and complex urban areas. Hence, aerial thermal remote sensing (with high resolution spatial resolution) is are visible option to help in realistic assessment of surface temperature and characteristic of heterogeneous and complex urban areas related to it. Added to that aerial thermal remote sensing has temporal flexibility times to give the most normalized characteristic of the area and thus reduce the apparent bias due to solar and atmosphere distortion.

- Given the finding that surface temperature is negative correlated to vegetation; it is advisable to afforest regions that are currently available for planning, especially in highly built up areas and barren land. This will in turn reduced the surface temperature of the region and thus to a certain extent influence the micro-climate of the region.

- Further research could include utilizing more effective classification method, such as neural network or support vector machine and decision tree control classification method to reduce the classification errors and their vector machines to reduce the classification errors and their influence on the final result.

\section{REFERENCES:}

A.K.Tiwari, M.Kudrat and S.K. Bhan, "Vegetation Cover Classification in Sariska National Park and Surroundings" Journal of Indian Society of Remote Sensing, Vol.18, No.3, 1990, Pages 43-51

Abdussalam Ahmed Ibrahim, Using Remote Sensing Technique (NDVI) for Monitoring Vegetation Degradation in semi-arid lands and its relationship to precipitation: Case 
study from Libya, the 3rd International Conference on Water Resources and Arid Environments (2008) and the 1st Arab Water Forum.

Aslam Ahmad, A "Remote Sensing-GIS Evaluation of Urban Growth-Land Surface Temperature Relationships in Selangor, Malaysia", School for Social, Development and Environmental Studies,

AtikurRahman, Suni Kumar and Shahab Fazal "Assessment of Land Use/Land Cover Changes in The North-West District of Delhi Using Remote Sensing and GIS techniques " Journal of Indian Society of remote Sensing (December 2012) 40 (4):689-697

C.R. Suribabu, J. Bhaskar and T.R. Neelakantan "Land Use/ Land Cover Change Detection of Tiruchirapalli City, Indai, Using Integrated Remote Sensing and GIS Tools" Journal of Indian Society of remote Sensing (December 2012) 40: 699708

Debasish Roy Raja, "Spatial Analysis of Land Surface Temperature in Dhaka Metropolitan Area", Journal of Bangladesh Institute of Planners Vol. 5, December 2012, PP. 151-167.

Inderjit Shngh, "Monitoring of Forest Cover Type and Land use Classes Through Remote Sensing Techniques (A Case Study in Ranikhet Tehsil,U.P.)"Journal Of The Indian Society of Remote Sensing, Vol.17, No.2, 1989

Janak P. Joshi and *Bindu Bhatt "Estimating Temporal Land Surface Temperature Using Remote Sensing: A Study of Vadodara Urban Area, Gujarat" international Journal of Geology, Earth and Environmental Sciences ISSN: 2277-2081

Javed Malik, "Satellite Based Analysis of Yhe Role of Land Use/Cover and Vegetation Density on surface Temperature Regime of Delhi, India."International Science for GeoInformation Science and Earth Observation Enchedg, the Netherlands \& Indian Institute of Remote Sensing, National Remote Sensing Agency (NRSC) Dehradun, India.

Malini A Shettynd R.K. Somashekar, "Assessment of Vegetation Cover Through NDVI, Bangalore India" Volume: 4 | Issue: 3 | Mar 2014 | ISSN - 2249-555X

Maria Bobrinskaya ,"Remote Sensing for Analysis of Relationships between Land Cover and Land Surface Temperature in Ten Megacities"TRITA-GIT EX 12-008

Odindi, J. O.1* and Mhangara "P.2, Green Spaces Trends in the City of Port Elizabeth from 1990 to 2000 using Remote Sensing”'Int. J. Environ. Res., 6(3):653-662, Sumer 2012

QihaoWenga,*, Dengsheng Lub,1, Jacquelyn Schubringa "Estimation of Land Surface Temperature-Vegetation Abundance Relationship for Urban Heat Island Studies"
Remote Sensing of Environment 89 (2004) 467483(www.elsevier.com/locate/rse)

Ram Babu Singh 1,*, Aakriti Grover 2 and Jinyan Zhan 3 "Inter-Seasonal Variations of Surface Temperature in the Urbanized Environment of Delhi Using Landsat Thermal Data"Energies2014, 7, 1811-1828; doi: 10.3390/en7031811

T. Murali Krishna. G. Ravi Kumar. And M. Krishnaveni 'Remote Sensing Based Agriculture Drought Assessment in Polar Basin of Tamilnadu State, India' Journal of Indian Soc. of Remote Sensing(March 2009) 37:920.

The Yale Center for Earth Observation "Converting Landsat TM And ETM+ Thermal Bands To Temperature" http://www.yale.edu/ceo

Togesh Kant And K.V.S Badarinath, Génération of Fraction Images From AVHHR Data Using Linear Mixing Model, journal of the Indian society of Remote Sensing, vol.26, No. $1 \& 2,1998$.

Ajmer-Wikipedia, the Free Encyclopedia "Ajmer Study Area Paper" http://en.wikipedia.org/wiki/Ajmer.

Services International LTD Ajmer Climate/ Weather/ Rainfall http://www.delhitouris .com/climate-ajmer.html. 